fogether with the curvature of the spinal column. But 1 cannot help thinking that as time goes on the tissue of the lung on the affected side undergoes some secondary developmental changes that lead to a considerable restoration of its useful powers.

Before concluding I would direct attention to a practical point in the management of these cases which $I$ have found of considerable use. After the operation of resection of a rib for empyema, difficulty is not infrequently experienced in completely emptying the lower portion of the pleural cavityi. e., that portion of it which lies below the level of the opening in the wall of the chest. To overcome this difficulty $T$ have found it best to get the patient close to the edge of the bed in a sitting position on the right or left side, according to which pleural cavity is to be emptied, and then to instruct him to place his right or left hand palm downwards on to the ground and to gradually lower his head on to the back of his hand. By this means the lower part of the pleural cavity is raised and can be easily emptied when a tube had been introduced into it before resecting the rib. If the patient is weak and unable to raise himself, he can still be gently placed without danger into this position, with his head resting upon a pillow, on the ground. In the three cases of empyema I have treated by resection I have found this method of emptying the lower portion of the pleural cavity exceedingly useful.

Hyderabad, Deccan.

\section{OBSERVATIONS ON THE ADMINISTRATION OF NITROUS OXIDE GAS.}

BY PERCY EDGELOW, L.R.C.P. EdIN., M.R.C.S, AN.ESTHETIST TO THE NATIONAL DENTAL HOSPITAL.

IN offering the following remarks on the administration of nitrous oxide gas, it is with the belief that they appertain in some measure to its successful administration.

It may seern superfluous to premise that whatever form of apparatus be used it should be in sound working order. I have, however, in not a few instances observed a faultiness in the accuracy of the fittings of its component parts which interferes with the perfect administration of the gas. The improved pedal attachment which I devised prevents any waste of gas in addition to its other distinct advantages, as explained in THE LANCET of Dec. 13th, 1890. With regard to the bag, I prefer one capable of holding three gallons, and connected at one end with the pedal attachment (a silencer intervening) by a broad tube of about $30 \mathrm{in}$. in length, and at the other end with the face-piece by a broad tube of about 25 in. in length. A distended bag conmected immediately with the face-piece is to many patients a source of intimidation; whereas, with the intervention of some length of tubing, so as to let the bag rest well out of view of the patient, sensitive feelings are less aroused. The valves of the face-piece should be invariably tested prior to each administration. The margin of the face-piece should, in its entirety, be in contact with the face; upon their accurate coaptation greatly depends the absence of that feeling of extreme tension in the head, which usually ensues where less care is observed. The supplemental bag I entirely discard, and this for many reasons. Thave failed to observe a longer period of unconsciousness from a to-and-fro breathing with it than from the inhalation of pure gas. I am convinced that a patient recovers from the effect of pure gas with less chance of unpleasant feelings, such as giddiness, headache, \&c., than when the supplemental bag has been used. The anesthesia produced with it is of a mixed nature, partly asphyxial, and only partly true nitrous oxide narcosis. Again, it is a most unhygienic arrangement. In view of the continual forward and backward breathing of all sorts and conditions of patients, this must necessarily be so, unless the interior of the bag be thoroughly cleansed after each administration, a proceeding very difficult to carry out. The only points that can possibly be urged in its favour are that it promotes an economy of gas, and that it can be utilised for obtaining anresthesia when a full supply of gas is suddenly found wanting. This latter condition, however, can now be entirely discounted with the use of the improved pedal attachment. I am in the habit of observing the following rules in the operating room :-To reassure the patient of the practically absolute safety of the gas, and that the opera- tion, whether it be a dental one, the incision of an abscess, the slitting up of a sinus, the extraction of a toe-nail, or other small operation, shall be perfectly painless. To refrain from any special physical examination of the patient. If the heart's action is very weak, as indicated by the pulse, or said to be diseased, I enjoin the recumbent position as far as the operation will permit. To be perfectly satisfied that breathing is quite free and unimpeded by any article of dress. To allow two or three inhalations of air to commence with. To count slowly from one to twenty during the administration, directing the patient to see how far he or she can follow me. To allow the operation, if dental, to commence only when stertor is well marked and jactitation en évidence. Should the case, however, be the single or multiple incisions of deep-seated suppuration, where forceps or director requires to be inserted, or scraping performed, the breaking down of joint adhesions, or other operations not involving the mouth or nose, I direct that the operation can begin at the onset of stertor, continuing the inhalation during the operation as far as may be necessary, only removing the face-piece should the breathing become greatly embarrassed. To keep the patient in the same position until complete sensibility has returned and giddiness has quite passed off. I frequently administer gas to the same patient twice or three times following, with an interval of one or two minutes, should there be no headache or continued giddiness between each administration. A few days ago $\mathrm{I}$ was giving gas to a powerfully built young gentleman with massive jaws. The dentist, a very dexterous extractor, was quite unable to move the right upper second molar tooth during a first and second administration of the gas, although anæsthesia was deeply induced. After waiting two minutes I gave it a third time, again very deeply, and on this occasion the tooth yielded, being a perfect specimen of a most difficult extraction, with three large and divergent roots. The patient recovered from the effect of the third inhalation as completely as from the first. With children I find it better to remove the facepiece almost immediately after the first signs of jactitation, as these so very often rapidly culminate in opisthotonos and other extreme convulsions of the body.

old Burlington-street, $\mathrm{w}$.

\section{di attirror}

\section{HOSPITAL PRACTICE, BRITISH AND FOREIGN.}

Nulla autem est alia pro certo noscendi via, nisi quamplurimas et morborum et dissectionum historias, tum aliorum tum proprias collectas
habere, et inter se comparare.-MoRGAGN De Sed. et Caus. Morb., lib. iv. Procmium.

\section{UNIVERSITY COLLEGE HOSPITAL.}

OLD-STANDING (? CONGENITAL) DISLOCATION OF PATELLA; REDUCTION OF PATELLA AFTER DIVIDING THE VASTUS

EXTERNUS AND CHISELLING A NEW TROCHLEAR

SURFACE ON THE FEMUR; RESTORATION OF FUNCTION OF THE LIMB.

(Under the care of Mr. BILTON Pollard.)

WE publish this week the account of a patient recently shown at the Clinical Society by Mr. Pollard. The history of the case is unusual. There is the statement of weakness in the limb of some kind in early life, then the supervention of genu valgum on the same side, which it was necessary to correct by means of an operation (a deformity of limb so frequently found in patients who have sustained traumatic dislocation of this bone). From the condition of the external condyle as found at the operation it is probable that the displacement was due, in a large extent, to want of development of that part of the femur, an occasional cause, as we have already mentioned when previously writing of dislocations of the patella ${ }^{1}$ which are not obviously due to severe injury. The other causes given are : sudden muscular contraction in patients the subject of knock-knee, ${ }^{2}$ weakness, or shortening of the quadriceps 
extensor following infantile paralysis ; some mechanical cause acting during intra-uterıne life; some congenital weakness of the part. ${ }^{4}$ Previous relaxation of the ligaments of the joint is considered necessary by Professor Steubel..$^{5}$ Hamilton ${ }^{6}$ says: "In some persons there appears to exist a preternatural laxity of the ligamentum patellie or of the quadriceps extensor, which exposes the subject to this accident from a very slight cause. The operation performed by Mr. Pollard is, we believe, the first of the kind that has been done. The operations suggested or others performed for the remedying of the condition on failure of apparatus to correct the ill effects of the dislocation have been: 1. A lateral incision and the suturing of the inner edge of the bone to the tissues on the inner side of the joint, the patella having been pushed well inwards (Wright). 2. Removal of the patella (Fowler). 3. Osteotomy of the femur and the production of a condition of bow-leg (Davies-Colley). The operation, a severe one, has been most successful. The following description is from notes by Mr. Raymond Johnson, late surgical registrar.

The patient was a young woman aged twenty-one years, who had followed the occupation of a domestic servant. She could not fix the period at which her patella became displaced. The affected limb had been weak from child. hood, but neither the patient nor her sister had noticed anything wrong with the knee. In December, 1885, she slipped and fell, but did not notice that anything had happened to her knee, and she was able to walk a distance of a quarter of a mile to her home. Since the accident she had walked lame. A few weeks later she was admitted to University College Hospital, under the care of Mr. Marcus Beck. She had well marked genu valgum on the left side, and when she attempted to bend her knee the patella slipped down on the outer side of the external condyle of the femur.

On Jan. 28th, 1886, Mr. Beck performed Macewen's operation for genu valgum, which was completely and permanently corrected thereby, but the readiness with which the patella became displaced during flexion of the knee was in no way altered. The dislocation of the patella was the source of much pain, and the patient said that it incapacitated her from following her occupation. She was readnitted to the hospital in December, 1890, and during the Christmas vacation, owing to Mr. Beck's absence, she came under the care of Mr. Pollard. The left knee was smaller than the right one. When the limb was extended, the inner edge of the left patella projected more forwards than natural, and lay in about the mid.line of the limb. At a little distance internal to the inner border of the patella a ridge could be felt, which appeared to be the inner border of the trochlear surface of the femur. Between this ridge and the patella there was a slight groove. When the patient bent her knee the patella slipped down on the outer side of the external condyle of the femur, and no force could prevent the displacement as soon as a few degrees of flexion had been made. Flexion was painful, but was possible to a few degrees beyond a right angle. The width of the right patella was an inch and a half, and that of the left was three-eighths of an inch less.

On Dec. 30th Mr. Pollard operated as follows: The limb being rendered bloodless by means of Esmarch's bandage and tourniquet, and tre skin being most carefully cleaned, an incision about two inches in length was made outside and above the patella, and the insertion of the vastus externus and the outer part of the capsule of the joint were freely divided, but it was still impossible to replace the patella or to prevent its slipping on the outer side of the condyle when the knee was bent. An incision about 3 in. long was now made a little internal to the inner border of the patella, and the joint was freely opened at this spot. The trochlear surface of the fenur was found to be exceed. ingly small in all its dimensions. The groove was only broad enough to take the little finger, and the outer border of the groove prevented the replacement of the patella, which, even in the extended position of the limb, was found to rest on the external condyle, ou tside the trochlear surface. The cartilage and some of the bones were chiselled away until a sufficiently broad and deep trochlear surface was made. The patella could then be placed on the new articular surface, and during flexion and extension it slid

3 Malgaigne; also Pitts, Med. Soc. Trans., vol. xii.

4 Wright and Ashby, Diseases of Children, p. 648, and others. Holmes' Surgery, p. 464 .

6 Fractures and Dislocations, p. 893. downwards and upwards in a perfectly normal manner, the old tendency to external dislocation having quite dis. appeared. In order to secure the patella more safely in its new position, a strip of capsule about $1 \frac{1}{2}$ in. long and 3 in. wide in the middle was excised and the: borders of the wound were sutured with silk. In this way the inner side of the capsule was braced up. During. the operation the wound was constantly irrigated with a 1 in 4000 solution of perchloride of mercury. The inner skin wound was completely closed, but the outer, which was made to penetrate the joint at the lower part, was left open at this spot, in order to give vent to any effusion which might take place within the joint. No tube was employed. The knee was dressed with cyanide of mercury gauze and sal alembroth wool. The limb was fixed in a trough of Gooch's splint. The temperature reached $99.8^{\circ}$ in the evening of the first day after the operation; it then gradually fell, and reached the normal on the fourth day. The patient had a good deal of pain in her knee on the day after the operation, but after the second day she was free from spontaneous pain. The dressing was changed on the eighth day after the operation. The discharge was dry. The knee was alternately passively flexed and extended. The movements caused much pain, and the patella was felt to grate against the bony surface of the new trochlear articular surface, but the patient was able to flex and extend her knee voluntarily. The patella showed no tendency to slip from its position. Passive movement was repeated on the thirteenth, fifteenth, and nineteenth days. The stitches were removed on the fifteenth day after the operation. On the twenty-first day the patient was allowed to get up, and on the twenty-eighth day she was able to walk down the ward. She went home on the thirty-second day after the operation. The patient was shown at the Clinical Society on A pril 24th. It was then four months after the operation. The movements at the knee joint were free and painless ; there was a little grating as the patella. slid over the new trochlear surface. The patient said that her leg was stronger and more serviceable tban before the operation. She had resumed her occupation as a domestie servant, and was able to scrub out four bedrooms and walk: four miles in one day without any inconvenience to her knee.

\section{JOHANNITER HOSPITAL, BEIRUT, SYRIA.}

A RECORD OF SOME CASES INJECTED WITH TUBERCULINUM: KOCHII.

(Under the care of Dr. H. Graham.)

THE line of treatment followed has been that described by Professor Libbertz, the commencing injection in all cases of phthisis being $0.001 \mathrm{grm}$. The fluid was diluted with distilled and sterilised water, and the dilution raised to the boiling point each time after the patients had been injected? before again closing the tube with cotton. The sputa were in every case examined before the patient was put under treatment, and the tubercle bacillus was found. The day after each injection the sputa were again examined in each case to see if any change had taken place. Each patient. was carefully weighed once a week, and the weight recorded to determine whether there was gain or loss.

CASE 1.-E-, a carpenter aged twenty-two. His. family history is good, and he himself is well built, but nervous-looking, with clear white skin, and hectic spots on. his cheeks. He entered the hospital on Feb. 5th, complain. ing of cough, feverishness, and some emaciation, from which he had been suffering about two months, but up to that. time had been in excellent health. He complained of weakness and loss of appetite, but had no night sweats. On the right apex there was dulness, increased vocal resonance, prolonged and roughened expiratory sound, and a few sub. crepitant râles. A few bacilli were found in about half the cover glasses examined. The first injection was followed by a marked reaction, but in no case did his temperature rise higher than $39^{\circ} \mathrm{C}$., so that the dose was rapidly raised, and on March 8 th he was given $0.150 \mathrm{grm}$. without any reaction. The physical signs had cleared up and his cough with expectoration had ceased. He was discharged on March $9 \mathrm{th}$, and since that time has been constantly under observation, and there have been no signs whatever of a return of his disease. 